\title{
Impact of Different Decontamination Processes on the Reduction of Pesticide Residues in Fruits and Vegetables
}

\author{
Anita ${ }^{1}$, Sushil Ahlawat ${ }^{2}$ and Sudesh Devi ${ }^{3^{*}}$ \\ ${ }^{1}$ Department of Chemistry, ${ }^{2}$ Department of Entomology, ${ }^{3}$ Department of Agronomy, CCS \\ Haryana Agricultural University, Hisar-125004, Haryana, India \\ *Corresponding author
}

Key w o r d s
Pesticide residue,
Processing,
Decontamination,
Washing, Peeling
off

A B S T R A C T

In order to increase agricultural production different type of pesticides viz., organochlorines, carbamates etc. are used on large scale to kill unwanted insects, pests, plants etc.; as mode of action of most of them is not specific, they often harm or kill organisms other than pests, including humans. Residues of most common pesticides could affect the ultimate consumers (animal and human) especially when pesticide treated fruit/vegetables are consumed raw. Proper processing technique in daily use of vegetables and fruits i.e. washing, peeling boiling, cooking, frying, sun drying etc. should be employed in order to avoid consumption of pesticides in food products. In the existing review, an effort has been made to appraise effect of different processing methods on the reduction of pesticides residues in different type of fruit and vegetable crops. Effectiveness of any decontamination methods vary with type of pesticide, location and age of residues in fruit/vegetable. In many studies, peeling was found to be effective method compared to other, for those fruit/vegetable in which most residues accumulated in topmost layer. Washing is also an effective method for decontamination of pesticide residues but its effectiveness depends upon number of factors like water solubility, temperature and type of washing solution.

\section{Introduction}

Several factors in crops limit their productivity, mainly insect, pests and diseases. The present day agriculture has enabled mass and stable production of food items by use of pesticides. In general more pesticides are used in production of vegetables and fruits as they are more susceptible to insect and pests. In order to increase agricultural production different type of pesticides viz., organochlorines, carbamates etc. are used on large scale and as mode of action of most of them is not specific, they often kill or harm organisms other than pests, including humans.

The application of pesticides is often not very precise, and unintended exposures occur to 
other organisms in the general area where pesticides are applied. Pesticide exposure can cause a range of neurological health effects in humans such as memory loss, loss of coordination, reduced speed of response to stimuli, reduced visual ability, altered or uncontrollable mood and general behaviour, and reduced motor skills.

The fundamental problem of contamination of natural resources with chemical pesticide residues is because of faulty and hazardous agricultural practices at the farming level, where prescribed recommendations are often ignored. Residues of most common pesticides could affect the ultimate consumers (animal and human) especially when pesticide treated fruit/vegetables are consumed raw.

The rational recommendation of pesticides use need to be framed keeping in mind not only effective control of all pests but also the residues of these pesticides in food commodity must be within toxicologically acceptable limits. Residue analysis provides measures of the nature and level of different chemical contamination within environment and its level of persistence (Tayade et al., 2013). Proper processing technique in daily use of vegetables and fruits i.e. washing, boiling, cooking, frying, sun drying etc. should be employed in order to avoid consumption of pesticides in food products. In the existing review, an effort has been made to appraise effect of different processing methods on the reduction of different pesticides residues in fruit and vegetable crops.

\section{Pesticide residues in fruits/ vegetables and decontamination processes}

Different analytical methods viz., gas chromatography coupled with a mass spectrometer (GC-MS/MS), ultra performance liquid chromatography coupled with a mass spectrometer (UHPLC-MS/MS) are used in residue analysis of fruits and vegetables (Anita and Sharma, 2018). To estimate the potential pesticide exposure on humans from contaminated food, it is important to estimate the level of exposure at the point of consumption after processing. During decontamination processing, it was reported that the main residues in potato were lindane, heptachlor and its epoxide, DDT and its derivatives, as well as malathion, pirimiphosmethyl, profenofos and dimethoate (Abou-Arab, 1999; Soliman, 2001). It has been reported that commercial and household processing such as washing, peeling, cooking, blanching, ozonating and concentrating can reduce pesticide residue levels in food and hence their adverse impact on human health (Abou-arab, 1999; Chung, 2017). It was determined by Priyadarshini et al., (2017) that residues of Triazophos, Chlorpyriphos, Ethion, Carbendazim, Cypermethrin and Profenofos in curry leaf samples got substantial reducted by different household processing methods. The reduction percentage for different processes is presented in Figure 1.

\section{Different household processes}

Dhiman, (2003) noted the effect of household processing on the reduction of pesticide residues in cauliflower. Washing reduced 28.92 to $78.64 \%$ residues in cauliflower treated with chlorpyriphos, quinalphos, endosulfan, fenvalerate and deltamethrin. The effect of different washing solutions such as acetic acid, sodium chloride etc. and kitchen processing such as washing, boiling/cooking on the removal of pirimiphos-methyl residues from vegetables was investigated by Radwan et al., (2004). Results indicated that acetic acid, potassium permanganate, sodium chloride and sodium hydroxide solution were more effective in removal of pirimiphosmethyl residues from sweet pepper and eggplant fruits. In hot pepper fruit, 70.16 and 
$76.61 \%$ reduction in residue was reported after washing with soap and acetic acid solution, respectively. Blanching and frying of pepper and egg-plant fruits resulted in almost complete removal $(\sim 100 \%)$ of the deposited pirimiphos-methyl. In addition, pickling process removed 86.29 and $92.34 \%$ residues from hot pepper fruit after one and two weeks, respectively.

Kumari (2008) in a monitoring study determined residue levels of organochlorines (OC), synthetic pyrethroids (SP), organophosphates (OP) and carbamates in three unprocessed vegetables viz. brinjal, cauliflower and okra, and evaluated the effect of different household processes (washing and boiling/cooking) on reduction of their residues from vegetables. Residues were estimated by using multi residue analytical technique employing gas liquid chromatography (GLC) with electron capture detector (ECD) and nitrogen phosphorus detector (NPD) equipped with capillary columns. Maximum (77\%) reduction of OP residues was observed in brinjal, followed cauliflower and okra by washing. Similar trend was observed under boiling process, where maximum (100\%) reduction of OP insecticides was observed in brinjal followed by $92 \%$ in cauliflower and $75 \%$ in okra. Boiling was found to be more effective as compared to washing in reducing the pesticide residues. Randhawa et al., (2008) based on their study, reported that cooking lowered the deltamethrin residues from 19 to $40 \%$ in vegetables.

Thanki et al., (2012) studied the effect of washing, boiling and cooking processes on the reduction of different insecticide residues in cauliflower and results are shown in Table 1. According to findings of this study washing, boiling and cooking processes minimized the pesticide residues of nine pesticides in the range of 3.32 - 70.0, 21.08 - 70.67 and 31.63 $85.30 \%$ respectively. According to Liang et al., (2012) organophosphorus pesticides reduced from $31.1 \%$ to $98.8 \%$ after washing with detergent solutions for $20 \mathrm{~min}$. Among detergent solutions, 5\% sodium carbonate solution recorded highest reduction in trichlorfon and dimethoate, and 5\% sodium bicarbonate solution reported higher reduction in dichlorvos, fenitrothion and chlorpyrifos. Pesticides residue reduction by $60.9-90.2 \%$ was reported under storage at $4{ }^{\circ} \mathrm{C}$ for 48 hours. Ultrasonic cleaning for $20 \mathrm{~min}$ lowered pesticides residue by $49.8-84.4 \%$. Rowayshed et al., (2013) illustrated that grilling process caused the reduction of aldicarb, pirimicarb, methomyl, carbaryl and mancozeb in eggplant fruits by $85.77,86.19,81.64,89.40$ and $84.26 \%$ from the residues of prepared fruits sample, respectively. Stewing (at $95 \pm 5{ }^{0} \mathrm{C}$ for 30 minutes) caused the reduction of carbamate pesticide's residues in eggplant fruits by 93.5 $100 \%$. Microwaving process led to a reduction of tested carbamate pesticides residues in eggplant fruits by about 82.95$90.46 \%$ and deep-fat frying process caused the complete disappearance of all tested carbamate pesticides.

According to Tomer and Sangha (2013), after boiling, organophosphates reduced by 32$100 \%$ in brinjal followed by $92 \%$ in cauliflower and $75 \%$ in okra. Boiling reduced trifloxystrobin residues in green chillies upto 50\%. Mirani et al., (2013) carried out studies on tomato sprayed with lufenuron pesticide and determined the effect of various traditional processing techniques such as washing, detergent washing, blanching, drying (either by sun-drying or thermal dehydration) and cooking/frying etc. on the extent of removal/reduction of pesticide residues contents. On basis of these studies, they reported that unwashed unprocessed samples contained the residues of lufenuron up to 1.75 ppm which was far above the maximum residue limits (MRL). The results further revealed that among the traditional processing 
plain water washing reduced the lufenuron residues up to $29.71 \%$, whereas detergent washing reduced the residues up to $48 \%$. Sun drying reduced lufenuron residues by 82.86 $94.77 \%$, which was significantly higher than thermal dehydration i.e. $81.26-91.71 \%$. Fried samples showed reduction of residues by 84.74-96.18\%. Blanching also had a significant effect on reduction of residues. It was observed that washing with running water and various chemical solutions used for domestic washing and commercial use are necessary to decrease lufenuron residues whereas boiling/ cooking is more effective in reduction of its residues.

Sheikh et al., (2014) studied the effect of processing on the reduction of pesticide residues in chilli with six pesticides, i.e. bifenthrin, profenofos, endosulfan, imidacloprid, emamectin benzoate and diafenthiuron. Bifenthrin was reduced by sundrying to the extent of $94.42-92.44 \%$ in the dehydrated chamber. Plain washing reduced the residues by $12.12 \%$ and detergent washing reduced by $24.24 \%$. Frying of sample reduced the pesticides by $99.02 \%$. Residues of profenofos were reduced up to 4.89 and $8.44 \%$ by plain washing and detergent washing, respectively. Subsequent frying reduced the residues up to $97.95 \%$, while dehydration and sun drying contributed 90.34 and $93.11 \%$ reduction. Diafenthiuron showed maximum reduction under sun drying and dehydration by 93.04 and $95.15 \%$ respectively Cooking/frying decreased the residues up to the level of $92.23 \%$. Sun dried and dehydrated samples showed the reduction of pesticide up to 99.08 and $95.12 \%$, respectively.

Fig.1 Percentage removal of pesticide residues from curry leaf by various decontamination methods (Priyadarshini et al., 2017)

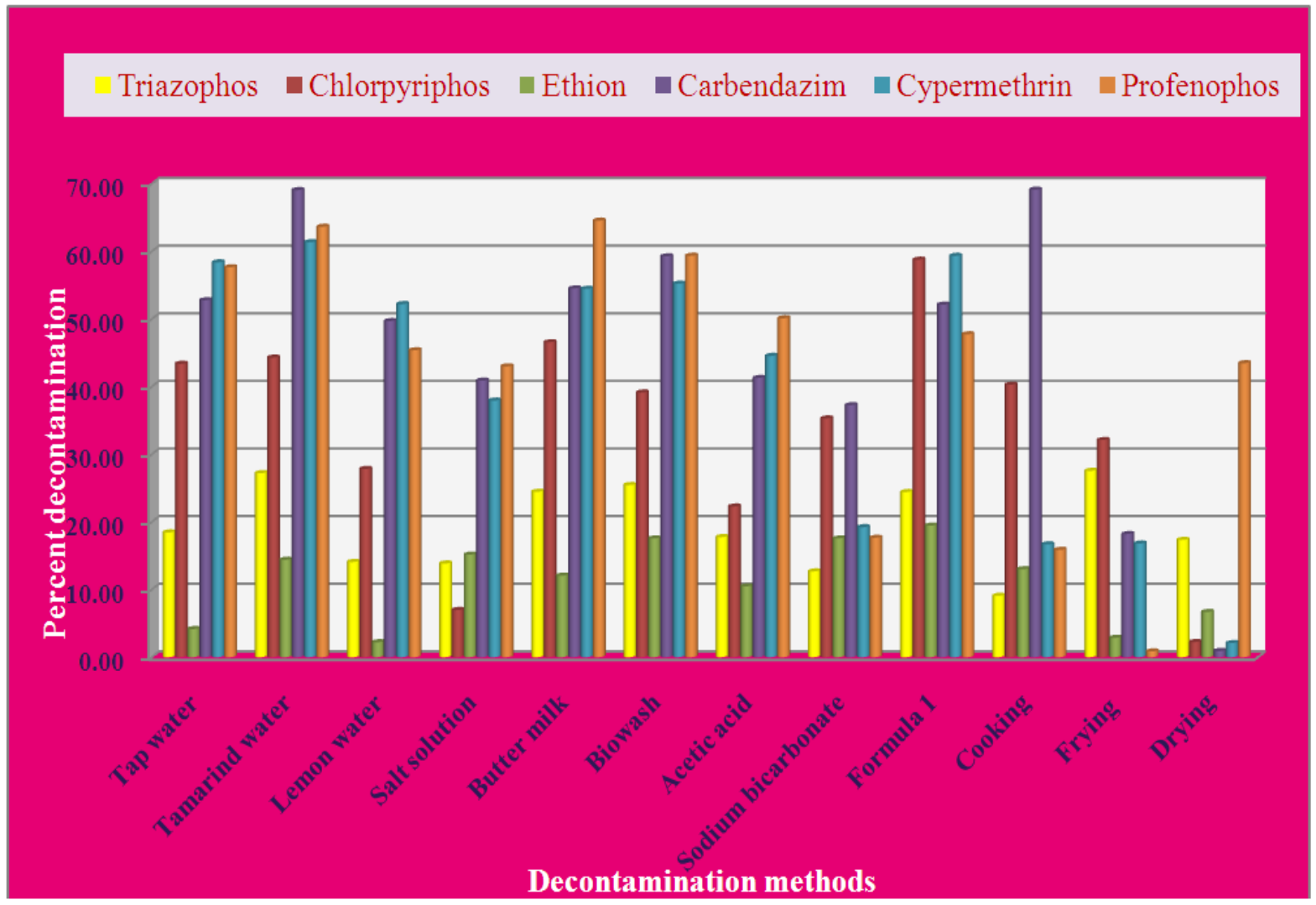


Table.1 Effect of different processing methods on reduction pesticide residues in cauliflower (Thanki et al., 2012)

\begin{tabular}{|c|c|c|c|}
\hline \multirow{2}{*}{$\begin{array}{c}\text { Name of } \\
\text { Pesticides }\end{array}$} & Percentage reduction of pesticide residues over unprocessed cauliflower \\
\hline Dichlorvos & Washing & Boiling & Cooking \\
\hline Monocrotophos & 3.32 & 51.62 & 67.46 \\
\hline Phorate & 70 & 70.67 & 85.30 \\
\hline Parathion & 16.27 & 44.34 & 68.87 \\
\hline Pendimethalin & 48.26 & 70.26 & 80.98 \\
\hline Endosulphan-II & 27.38 & 59.82 & 61.61 \\
\hline Captafol & 33.26 & 45.64 & 53.22 \\
\hline Penmethrin & 23.44 & 45.31 & 78.91 \\
\hline Cypermethrin & 6.80 & 21.08 & 31.63 \\
\hline
\end{tabular}

Thanki et al., (2015) reported that for common household processes, maximum reduction of residues were observed in case of pesticides cypermethrin, captafol and parathion where their residues decreased to the extent of $83.87,64.78$ and $54.14 \%$ by washing process respectively. It was found that washing and cooking processes minimized the pesticide residues in the range of $1.74-64.78 \%$ and $38.40-90.15 \%$ respectively. Reduction of residues depends on a number of factors like, location and age of residues, water solubility, temperature and type of washing solution. Effect of ozonated water on the reduction of insecticides residues in potatoes was determined by Marzouk and Mohamed (2014). Results showed that five organophosphorus (chlropyrifos, fentrothion, profenofos, agrothion and indoxacarb) and two carbamate insecticides (carbosulfan and methomyl) were detected and their residues, in most cases exceeded the maximum MRL. Ozonated water had profound effect in reducing insecticides residues and the potency of reduction was increased with increase in concentration of ozonated water. Results indicated that ozonated water removed the indoxacarb residues from the detected levels of $2.0 \mathrm{ppm}$ to $1.0 \mathrm{ppm}$ and 0.0 at the low and high doses, respectively, in potato samples.
Dhiman and Hiremath (2014) observed maximum reduction in concentration of indoxacarb $(79.244 \%)$, moderate reduction in chlorpyrifos (67.162\%) and profenophos $(54.354 \%)$ and very minimal reduction in cypermethrin $(6.991 \%)$ by traditional processes i.e. washing with tap water. Washing with boiled water significantly reduced prefenophos (97.379\%) and indoxacarb (95.588\%). Chlorpyriophos $(55.019 \%)$ was moderately reduced and minimal reduction was found in cypermethrin (29.841\%) as compared to others. Cauliflower samples which were washed with boiled water, found to have significantly lower concentration of chlorpyriphos, indoxacarb, prefenophos and cypermethrin. Tap water considerably reduced indoxacarb (79\%) and chlorpyriphos $(67 \%)$ residues.

\section{Effect of peeling on reduction of pesticide residues in vegetables}

Impact of peeling on carbamate pesticides in raw tomato fruits was shown by Rowayshed et al., (2013). Peeling by hot water at $95^{\circ} \mathrm{C}$ for 2 min eliminated concentration of 0.797 , $0.628,0.916,0.468$ and $1.069 \mathrm{ppm}$ of carbamate and caused the reduction of pesticides residues in prepared tomato fruits 
by $67.27,68.43,67.69,75.22$ and $63.43 \%$, respectively.

Shiekh et al., (2014), based on his studies concluded that bitter gourd peel had high amount of residues due to its thick peel, which adhere the majority of pesticide residues on the top. The processing methods played a major role in reducing the residues from the bitter gourd peel and render the vegetable suitable for human consumption by decreasing the residues within prescribed limits of MRLs. Kong et al., (2012a) reported that elimination of $\beta$-cypermethrin on apples through peeling and coring is in the range of $11-23 \%$. This is due to the fact that $\beta$ cypermethrin penetrates from the skin into the flesh of the apple. Pesticide residues of chlorpyriphos, tebuconazole, acetamiprid and carbendazim were reduced by more than 52 per cent through peeling and coring process.

In a different study, Kong et al., (2012b) reported that washing and peeling of tomato reduces the residues of difenoconazole by 99 per cent. Reduction of lindane levels in fortified tomatoes ranged from $15 \%$ (washing with tap water) to $82 \%$ (after peeling) as reported by Abou-Arab (1999). Reduction of residues of chlorpyriphos and cypermethrin in Asparagus was 73 to $75 \%$ after peeling as reported by Chavarri et al., (2005).

Peeling off potatoes reduced $91-98 \%$ chlorpyriphos residues from an initial concentration of $3.8 \mathrm{ppm}$ in individual tubers (Lentza and Balokas, 2001). The amount of pesticide residues removed by peeling was $70 \%$ for pyridaben and $100 \%$ for pyrifenox and tralomethrin (Boulaid et al., 2005). The initial diazinon residue level $(0.822 \mathrm{ppm})$ on cucumber was decreased by $67.3 \%$ by peeling (Cengiz et al., 2006). Initial procymidone residues level $(0.86 \mathrm{ppm})$ on tomatoes was decreased $77 \%$ by peeling procedure (Cengiz et al., 2007).
Randhawa et al., (2007) reported that peeling decreases chlorpyriphos residues by 65 and $85 \%$ in potato and eggplant, respectively. Peeling process had a significant effect on the removal of chlorpyriphos residues in eggplant and potato because of lower penetration power of these compound and incorporation of these into cuticle layer of the plant and hence can be removed to a higher extent by peeling (Dejonckheere et al., 1996). Peeling of potato skin removed more than $99 \%$ of fenitrothion residues from $1.43 \mathrm{ppm}$ present on potatoes one day after treatment (Hegazy et al., 1988). Peeling off the mango fruit skin was found to be effective in removing the pesticide residues of dimethoate, fenthion, cypermethrin and fenvalerate completely; due to the accumulation of their residues in the fruit pericarp only and no further movement of these residues to fruit pulp (Awasthi, 1993).

From survey of literature it can be concluded that effectiveness of different decontamination process for reduction of different pesticides residues vary with type of pesticide, location and age of residues in fruit/vegetable and fruit/vegetable type. Peeling was found to be effective method compared to other for that fruit/vegetable in which most residues accumulate in topmost layer. Washing is cheap, fast and effective method for decontamination of pesticide residues but its effectiveness depends upon number of factors like vegetable/fruit type, water solubility, temperature and type of washing solution. Other methods like boiling, sun drying, frying etc. can be employed at home and can be effective method for decontamination for some pesticides.

\section{References}

Abou-Arab, A.A.K., 1999. Behaviour of pesticides in tomatoes during commercial \& home preparation. Food Chem., 65: 509-514. 
Anita and Sharma, B., 2018. Review on Analytical Techniques used for the Estimation and Persistence of ReadyMix Formulation Residues in Various Crops and Soil. Int. J. Sci. Res., 7: 78 81.

Awasthi, M.D., 1993. Decontamination of insecticide residues on mango by washing and peeling. J. Food Sci. Technol., 30: 132-133.

Boulaid, M., Aguilera, A., Camacho, F., Soussi, M., and Valverde, A., 2005. Effect of household processing and unit-to-unit variability of pyrifenox, pyridaben, and tralomethrin residues in tomatoes. J. Agr Food Chem., 53: 4054 - 4058.

Cengiz, M.F., Certel, M., and Göçmen, H., 2006. Residue contents of DDVP (Dichlorvos) and diazinon applied on cucumbers grown in greenhouses and their reduction by duration of a preharvest interval and post-harvest culinary applications. Food chem., 98: 127-135.

Cengiz, M.F., Certel, M., Karakaş, B., and Göçmen, H., 2007. Residue contents of captan and procymidone applied on tomatoes grown in greenhouses and their reduction by duration of a preharvest interval and post-harvest culinary applications. Food Chem., 100: 1611-1619.

Chavarri, M.J., Herrera, A., and Arino, A., 2005. The decrease in pesticides in fruit and vegetables during commercial processing. Int. J. Food Sci. Technol., 40: 205-211.

Chung, S.W., 2017. How effective are common household preparations on removing pesticide residues from fruit and vegetables? A review. J. Sci. Food Agric. 2017 Dec 9. doi: 10.1002/jsfa.8821.

Dejonckheere, W., Steurbaut, W., Drieghe, S., Verstraeten, R., and Braeckman, H.,
1996. Monitoring of pesticide residues in fresh vegetables, fruits, and other selected food items in Belgium, 19911993. J. AOAC Int., 79: 97-110.

Dhiman, A. and Hiremath, S.K., 2014. A comparative study of effect on Brassica oleracea (cauliflower) using different washing methods W.S.R to estimation of pesticide residue. Global J. Res. Anal., 3:116-118.

Dhiman, N., 2003. Effect of processing on the pesticide residues in milk, selected cereals and vegetables. M.Sc. Thesis. Punjab Agricultural University, Ludhiana, Punjab.

Hegazy, M.E.A., Abdel-Razik, M., Diab, M.M. and Abu-Zahw, M.M., 1988. Sumithion residues on and in potato tubers. Ann. Agric. Sci., 33: 1291-1298.

Kong, Z., Dong, F., Xu, J., Liu, X., Zhang, C., Li, J., Li, Y., Chen, X., Shan, W. and Zheng, Y., 2012b. Determination of difenoconazole residue in tomato during home canning by UPLC-MS/MS. Food Control, 23: 542-546.

Kong, Z., Shan, W., Dong, F., Liu, X., Xu, J., Li, M. and Zheng, Y., 2012a. Effect of home processing on the distribution and reduction of pesticide residues in apples. Food Addit. Contam., 29: 12801287.

Kumari, B., 2008. Effects of household processing on reduction of pesticide residues in vegetables. J. Agric. Biol. Sci., 3: 46-51.

Lentza-Rizos, C., and Balokas, A., 2001. Residue levels of chlorpropham in individual tubers and composite samples of postharvest-treated potatoes. J. Agric. Food Chem., 49: 710-714.

Liang, Y., Wang, W., Shen, Y., Liu, Y., and Liu, X.J., 2012. Effects of home preparation on organophosphorus pesticide residues in raw cucumber. Food Chem., 133: 636-640. 
Marzouk, E.M.A. and Mohamed, M.S., 2014. Effect of ozonated water in reducing insecticides residues from potato tubers. Middle East J. Agric. Res., 3: 12141220.

Mirani, B.N., Sheikh, S.A., Nizamani, S.M. and Mahmood, N., 2013. Effect of household processing in removal of lufenuron in tomato. Int. J. Agric. Sci. Res., 3: 235-244.

Priyadarshini, G., Vemuri, S., Reddy, C. N., Swarupa, S., and Kavitha, K., 2017. Risk Mitigation for Removal of Pesticide Residues in Curry Leaf for Food Safety. Int. J. Agric. For., 7: 1322.

Radwan, M.A., Shibbob, M.H., AbuElamayem, M.M. and Abdul-Aal, A., 2004. Pirimiphos methyl residues on/in some field grown vegetables and its removal using various washing solutions and kitchen processing. Int. J. Agric. Biol., 6: 1026-1029.

Randhawa, M.A., Anjum, F.M., Ahmed, A. and Randhawa, M.S., 2007. Field incurred chlorpyrifos and 3, 5, 6trichloro-2-pyridinol residues in fresh and processed vegetables. Food Chem., 103: 1016-1023.

Randhawa, M.A., Anjum, F.M., Randhawa, M.S., Ahmed, A., Farooq, U., Abrar, M. and Randhawa, A.R., 2008. Dissipation of Deltamethrin on supervised vegetables and removal of its residue by household processing, J. Chem. Soc. Pak., 30: 227-231.

Rowayshed, G., Asraf, M.M.S. and Mahmoud, M.M., 2013. Stability of carbamate pesticides residue in some vegetables throughout the household processing and cooking. Middle East J. Appl Sci., 3: 205-215.

Sheikh, S.A., Panhwar, A.A., Mirani, B.N. and Nizamani, S.M., 2014. Effectiveness of traditional processing techniques on residual removal in chilies sprayed with various pesticides. J. Biodivers. Environ. Sci., 5: 365-370.

Soliman, K.M., 2001. Changes in concentration of pesticide residues in potatoes during washing and home preparation. Food Chem. Toxicol., 39: 887-891.

Tayade, S., Patel, Z.P., Mutkule, D.S. and Kakde, A.M., 2013. Pesticide Contamination in Food: A Review. $J$. Agric. Vet. Sci. 6: 07-11.

Thanki, N., Joshi, P. and Joshi, H., 2012. Effect of household processing on reduction of pesticide residues in cauliflower (Brassica oleraceae var. botrytis). Euro. J. Exp. Bio., 2: 16391645.

Thanki, N., Joshi, P., and Joshi, H., 2015. Effect of household processing on reduction of pesticide residues in tomato (Lycopersicon esculentum Mill). J. Chem. Pharm. Res., 7: 19972002.

Tomer, V. and Sangha, J.K., 2013. Vegetable processing at household level: effective tool against pesticide residue exposure. J. Environ. Sci. Toxicol. Food Technol. 6: 43-53.

\section{How to cite this article:}

Anita, Sushil Ahlawat and Sudesh Devi. 2018. Impact of Different Decontamination Processes on the Reduction of Pesticide Residues in Fruits and Vegetables. Int.J.Curr.Microbiol.App.Sci. 7(05): 869-876. doi: https://doi.org/10.20546/ijcmas.2018.705.106 